\title{
AS APARÊNCIAS ENGANAM OU SOBRE DIALOGISMO E REDES SOCIAIS
}

\section{LOOKS CAN BE DECEIVING OR ON DIALOGISM AND SOCIAL NETWORKING}

\section{SILVA, Adriana Pucci Penteado de Faria e}

Doutora em Linguística Aplicada pelo LAEL- PUCSP.

Docente do Instituto de Letras - Universidade Federal da Bahia

E-mail: appucci@uol.com.br

ORCID ID: https://orcid.org/0000-0001-6302-6521

\section{RESUMO}

Neste artigo, o objetivo é mostrar o diálogo com um corpus de análise construído a partir de uma experiência de interação em redes sociais. A base teórica e epistemológica emerge dos escritos de Bakhtin e dos demais pesquisadores do Círculo, em diálogo com pesquisas feitas por Amorim (2000, 2007, 2015) sobre formas de saber e de conhecimento e sua relação com interações discursivas de diferentes naturezas. Apresenta-se uma reprodução de frames da postagem no Instagram que gerou as interações em análise e mostra-se uma seleção de repostas a um comentário crítico. Pela análise de alguns aspectos linguísticos e discursivos dessas interações, flagra-se um discurso que contrapõe o Instagram ao Facebook, posicionando essas redes de acordo com os usuários que nelas deveriam circular. Conclui-se que há hábitos monologizantes exercendo certas coerções nas redes, mas aponta-se que, nas interações, existe a possibilidade de refração desses hábitos.

Palavras-chave: Bakhtin e o Círculo; redes sociais; formas de saber; hábitos monologizantes

\section{ABSTRACT}

In this article, the aim is to show the dialogue with an analysis corpus built from a catalytic experience resulting from interaction in social networks. The theoretical and epistemological bases emerge form Bakhtin and the Circle's works, in dialogue with research done by Amorim $(2000,2007,2015)$ about ways of knowledge and their rapport with different kinds of discursive interaction. A reproduction of some frames of a post in Instagram is presented. Such post provoked the dialogues under analysis. A select of answers to a critical comment is also presented. Through the analysis of some discursive and linguistic features of such interactions, it is possible to catch a discourse which opposes Instagram to 
Facebook, placing such networks according to the users that should be present there. As a conclusion, the article points at monological habits that play certain prescriptions on networks, but it also points at the possibility of refracting such habits.

Keywords: Bakhtin and the Circle. Social networks. Ways of knowledge. Monological habits

\section{A EXPERIÊNCIA CATALISADORA}

Num mundo já pandêmico, como tantas pessoas em parte avessas às redes sociais, comecei a navegar diariamente no Instagram. É um modo de conviver. Dentre as poucas páginas seguidas, elegi o perfil @pera_toons. Uma maneira de estar em contato com a língua italiana e de, por que não, rir um pouco. Trata-se de perfil em que se veem piadas ou "tiradas animadas" em vídeo (no original "battute animate'), produzidas pelo comediante Alessandro Perugini ${ }^{1}$.

Não sou uma usuária muito esperta nas prescrições da rede. Setembro de 2020. Eu, que não sabia que "seguir", nesse ambiente, poderia significar aplaudir qualquer coisa, em qualquer circunstância, fiz um comentário com uma crítica negativa a uma das piadas. Para minha surpresa, a reação negativa dos demais seguidores da página ao comentário foi bastante veemente. Reproduzo aqui a tirada, em dois prints da tela. No original ${ }^{2}$, há também áudio:

Figura 1 - primeiro frame e do vídeo com a tirada cômica
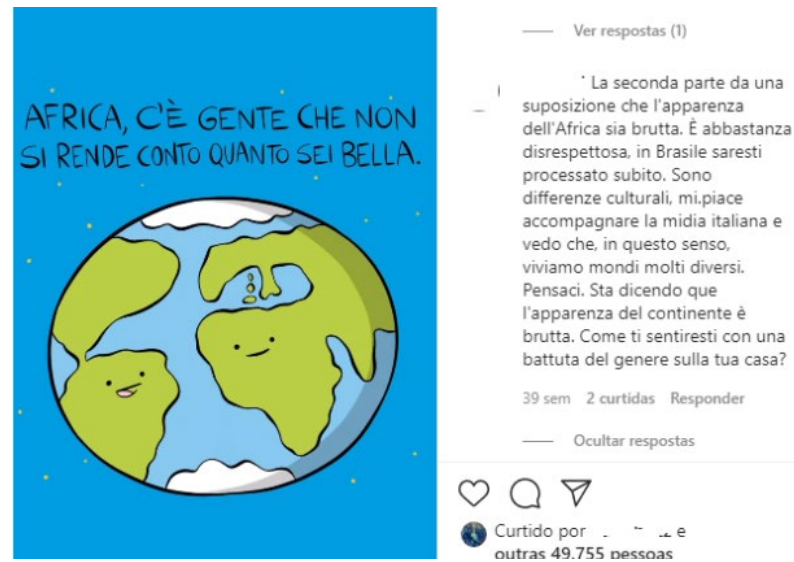

\footnotetext{
${ }^{1}$ Ver https://www.alessandroperugini.com/. Acesso em: 29 jun. 2021.

${ }^{2}$ Ver https://www.alessandroperugini.com/. Acesso em: 30 jun. 2021.
} 
Figura 2 - Frame final da tirada cômica
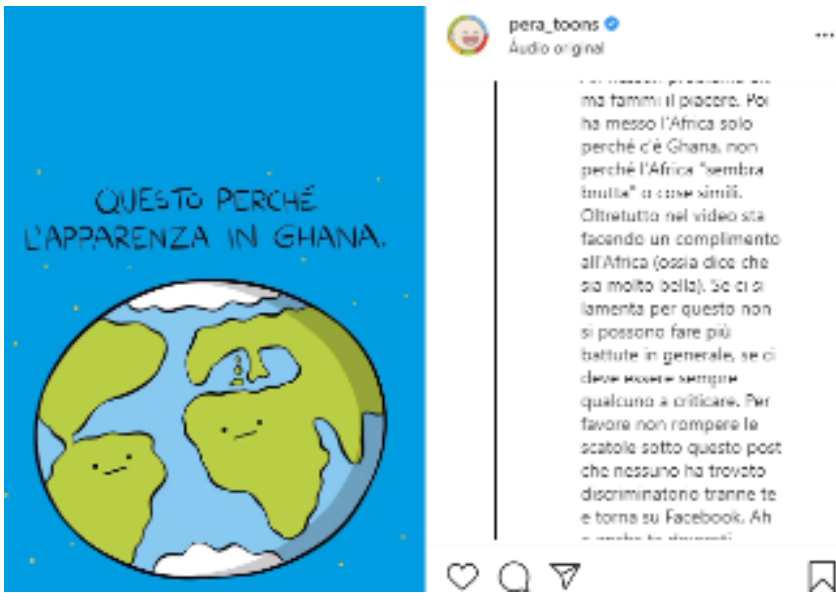

Pelo desenho, infere-se que a América do Sul estaria dirigindo a palavra à África, pois os dois continentes estão representados com características de personificação (boca e olhos), o que se confirma pelo vocativo "África" no frame 1. O texto da tirada, em tradução literal minha para o português, é o seguinte: Frame 1: "África, tem gente que não percebe como você é bonita". Frame 2: "Isto porque a aparência em Gana". O humor residiria no fato de ter-se a mesma sequência sonora para "em Gana", ou, seja, no país Gana, e no verbo enganar conjugado na terceira pessoa do singular do presente do indicativo, tanto em português como em italiano, o que remeteria, nas duas línguas, à frase feita "a(s) aparência(s) engana $(m) "$.

Meu comentário está impregnado de questões históricas, sociais e ideológicas de alguém que vive o Brasil do séc. XXI e conhece todos os avanços, ainda que insuficientes, na preservação do respeito às diferenças em nosso país. A análise se baseará na seguinte leitura: usa-se a expressão "a aparência engana" ou para se falar de algo aparentemente positivo que, em essência, é negativo, ou para mostrar que algo em aparência é negativo, mas, em essência, é positivo. Portanto, se há gente que não percebe a beleza da África porque a aparência engana, entendese que a aparência não é bela e que a beleza seria de outra ordem, "interior".

Além disso, pode estar subentendida no enunciado a polarização hemisfério norte $X$ hemisfério sul, pois temos dois continentes do sul na conversa. Quando um diz "tem gente que", entendemos que se refere a 
terceiros, a outros continentes que não são parceiros discursivos diretos na interação. Eis o comentário, em tradução literal para o português:

A segunda parte de uma suposição que a aparência da África seja feia. É bastante desrespeitosa, no Brasil você seria logo processado. São diferenças culturais, gosto de acompanhar a mídia italiana e percebo que, neste sentido, vivemos em mundos diferentes. Pense nisso. Você está dizendo que a aparência do continente é feia. Como você se sentiria com uma piada desse tipo sobre sua casa? (Ver FIGURA 1)

Essa crítica gerou 2 curtidas e 12 respostas com ela polemizando. Uma seleção dessas respostas será reproduzida mais adiante.

Meu objetivo nesta reflexão não é, de forma central, discutir o teor da piada, mas mostrar como uma resposta crítica no Instagram gerou enunciados que contêm julgamentos a quem escreveu a crítica, e indicações de que essa pessoa estaria desqualificada para circular na rede. Há, como veremos, a sugestão de que pessoas que criticam seriam velhas e deveriam estar no Facebook, não no Instagram. Não posso afirmar que não haja polêmicas nessa rede ${ }^{3}$, mas procuro investigar de onde vem 0 sentido, presente nas respostas em análise, de que aquele não seria um lugar para críticas.

Para perseguir tal objetivo, exporei algumas noções teóricas da análise dialógica do discurso que se podem depreender dos escritos de Bakhtin e dos demais pesquisadores que com ele trabalharam (aos quais damos a genérica denominação de Círculo). Em seguida, farei a descrição do diálogo polêmico que a crítica à postagem gerou, analisando, do ponto de vista discursivo, os pressupostos da interação em redes sociais.

\section{BAKHTIN E O DISCURSO DIALÓGICO E REFLEXÕES INICIAIS SOBRE FACEBOOK E INSTAGRAM}

Apontar em que obra ou trecho Bakhtin e as outras pessoas do Círculo discutem determinada noção teórica é tarefa ingrata. O mestre russo, de fato, desenvolveu sua filosofia /teoria ao longo de mais de cinco décadas, retomando conceitos em diversas obras, tratando, por vezes, de um mesmo fenômeno sob outro ângulo, com diferentes denominações. ${ }^{4}$

\footnotetext{
${ }^{3}$ Ver, por exemplo, < https://esquerdaonline.com.br/2020/07/26/sobre-aplicativos-criticas-e-tom-dapele/ $>$, sobre o uso crítico que Djamila Ribeiro faz de suas redes e a repercussão desse uso.

${ }^{4}$ Nesse sentido, ver as reflexões de Amorim (2009) sobre a origem do conceito de cronotopo e dialogismo no chamado período filosófico de Bakhtin, ou as análises de Zavala (2009) sobre ensaios
} 
A ideia de dialogismo ou discurso dialógico não escapa a esse modus operandi. Para meus propósitos neste trabalho, centrarei a busca do conceito na discussão que Bakhtin faz sobre o discurso em Dostoiévski na obra Problemas da poética de Dostoiévski ([1963] 2010), no ensaio Os gêneros do discurso ([1952-1953]2016a) e no recentemente disponível em português Diálogo 1. A questão do discurso dialógico ([?] 2016 b) ${ }^{5}$. Destacarei, ainda, algumas considerações feitas por Volóchinov em Marxismo e Filosofia da Linguagem ([1929] 2019).

A obra Problemas da poética de Dostoiévski (doravante PPD) circula em tradução para o português desde 1981, sendo bastante conhecida dos pesquisadores brasileiros. É Marxismo e Filosofa da Linguagem (Volóchinóv [1929] 2019), (doravante MFL), traduzido de forma indireta, do francês, pela primeira vez ao português em 1979 (Bakhtin (Volóchinov), 1995), nossa primeira fonte sobre os conceitos de discurso monológico e dialógico no pensamento bakhtiniano.

Em MFL, é bastante conhecida a crítica ao pensamento linguístico centrado nas tendências que Volóchinov denomina como subjetivismo idealista e objetivismo abstrato. Destaco, para este trabalho, que essas críticas têm como um dos pilares justamente o conceito de discurso monológico. Volóchinov critica o fato de que essas duas tendências consideram a linguagem partindo "principalmente do enunciado monológico" (2019, p 217). Nessa crítica, percebe-se que o aspecto monológico está não na língua, mas na mirada teórica e filosófica que se assume ao tomá-la como objeto de estudo.

Os termos "dialógico" e monológico", de fato, perpassam toda a discussão feita em MFL, sem que deles se exponha, contudo, uma definição didática. Mesmo assim, pode-se perceber que uma coisa é a realidade da língua em uso, ou "em sua integridade concreta e viva" (Bakhtin, 2010a, 207) e outra coisa é a forma de se pensar a língua. Quando converso com meu corpus, como mostrarei adiante, percebo na rede social uma tendência a estreitar o caráter dialógico da interação. Mas não se pode eliminar o dialogismo na interação, como afirma Volóchinov, ao criticar a linguística, ciência que partiria do enunciado morto, como um monumento, pela "necessidade filológica":

[...] o enunciado monológico já é uma abstração, apesar de ser, por assim dizer, uma abstração natural. Qualquer enunciado monológico, inclusive um monumento escrito, é um monumento indissolúvel da comunicação discursiva.

bakhtinianos desse período, a respeito da relação autor-herói na atividade estética.

${ }^{5}$ Embora tenhamos, na edição em português, a indicação de que esse trabalho de Bakhtin foi publicado em russo pela primeira vez em 1997, não há menção sobre a data em que ele teria sido escrito. 
Todo enunciado, mesmo que seja escrito e finalizado, responde a algo e orienta-se para uma resposta. Ele é apenas um elo na cadeia ininterrupta dos discursos verbais. Todo monumento continua a obra dos antecessores, polemiza com eles, espera por uma compreensão ativa e responsiva, antecipando-a etc. Todo monumento é uma parte real e indissolúvel ou da ciência ou da literatura ou da vida política. $(2019,184)$

Nas reflexões de Volóchinov, percebe-se a tensão entre os conceitos de enunciado monológico e dialógico que perpassa toda a obra do Círculo: ao entrar na cadeia discursiva, não há enunciado monológico que resista ao dialogismo, porque a interação aniquila a vontade monológica.

Nesse sentido, em PPD, ainda que o foco seja o discurso literário e a relação entre autor/narrador e personagens, percebe-se, da mesma forma, que a ideia de monologismo está ligada à visada teórica pela qual se abordam os fenômenos da linguagem. Bakhtin, ao analisar a relação discurso do autor e discurso do herói para mostrar a originalidade da prosa de Dostoiévski (o romance polifônico), faz reflexões sobre o discurso em geral. O pensador russo sustenta que estilística, linguística, lexicologia e outras ciências da linguagem permanecem "nos limites de um contexto monológico" e conhecem "apenas a orientação direta e imediata da palavra voltada para o objeto, sem levar em conta o discurso do outro, o segundo contexto" (Bakhtin, 2010, p.213).

Uma crítica centrada na palavra "de ninguém", para Bakhtin, apresenta "limites estreitos" tanto para a prosa como a poesia (2010a, p.231). A força da obra de Dostoiévski estaria, justamente, no fato de a palavra dos heróis não ser eco da palavra do autor. As personagens em Dostoiévski são capazes de inserir no romance a língua viva, o discurso independente da voz do autor, ainda que, para isso, se utilizem do autor como "uma correia de transmissão" (Bakhtin, 2010 , p.335 ). A voz do autor não apaga a voz dos heróis.

Ainda que o foco de Bakhtin em PPD seja a obra de Dostoiévski e sua relação com a palavra como forma de criação artística, podem-se depreender desse trabalho reflexões sobre o dialogismo como fenômeno que diz respeito à interação discursiva em geral. Nesse sentido, algumas reflexões do mestre russo me orientam para esboçar análises de interações que ocorrem no séc. XXI, em redes sociais, em plataformas que, evidentemente, não foram pensadas por ele. Isso é possível porque, ao fim e ao cabo, as interações em plataformas digitais são feitas por "membros de grupos falantes" (embora saibamos que, por vezes, podemos interagir com robôs nessas redes), e, para Bakhtin: 
Um membro de um grupo falante nunca encontra a palavra previamente como uma palavra neutra da língua, isenta das aspirações e das avaliações dos outros ou despovoada das vozes dos outros. Absolutamente. A palavra, ele a recebe da voz de outro e repleta de voz de outro. No contexto dele, a palavra deriva de outro contexto, é impregnada de elucidações de outros. O próprio pensamento dele já encontra a palavra povoada. Por isso, a orientação da palavra entre palavras, as diferentes sensações da palavra do outro e os diversos meios de reagir diante dela são provavelmente os problemas mais candentes do estudo metalinguístico de toda palavra, inclusive da palavra artisticamente empregada." (Bakhtin, 2010, p 232, grifos meus)

Quando Bakhtin afirma que suas reflexões se dirigem "inclusive" à palavra artisticamente empregada, dá-nos a possiblidade de entender que se dirigem também às palavras empregadas não artisticamente, como os comentários feitos em redes socais. Fazendo um paralelo entre ciências criticadas por Bakhtin por insistirem numa apreciação monológica dos fenômenos da linguagem (como a linguística e a estilística) e a cultura das redes sociais, seria possível pensar que nas redes há um direcionamento para o monológico em detrimento do dialógico? Ao final de minhas análises, fazendo referência também ao longa-metragem $O$ dilema das redes (2020), explorarei essa questão.

Por ora, ressalto que em Esboço de reformulação de PPD (Bakhtin, 2010) o autor registra, dentro de uma enumeração que parece ser o próprio esquema da obra, que há "potencialidade dialógica" no monologismo (p. 338) e que existiria, à época de suas reflexões, uma tendência a monologizar os romances de Dostoievski, o que, para o autor, deveria ser combatido com a "renúncia a hábitos monológicos" (p. 338). Essas notações do pensador russo me possibilitam inferir que a palavra, como a encontramos na vida (e as redes sociais fazem parte da vida) não pode ser monológica, mas há maneiras monológicas de perceber essa palavra, existe um "hábito" que nos levaria a monologizar o que lemos/ouvimos/percebemos.

Para finalizar um desenho possível dos conceitos de monológico/ dialógico na obra de Bakhtin e do(s) Círculo(s), passo a destacar alguns aspectos que estão no ensaio Os gêneros do discurso (2016 a, doravante GD) e em Diálogo 1. A questão do discurso dialógico (2016 b, doravante D1).

Em GD, que conhecemos desde 1992, em tradução indireta via francês e inglês, e em tradução direta do russo desde 1993, o foco de 
Bakhtin amplia-se, e ele discute de maneira ampla a relação entre parceiros discursivos em diversos gêneros. Criticando os esquemas linguísticos de comunicação, em que o "ouvinte" seria um receptáculo passivo de informações, sem a capacidade de negociar sentidos, o mestre russo dá grande ênfase ao caráter dialógico da "comunicação discursiva", afirmando que:

[...] toda compreensão plena real é ativamente responsiva e não é senão uma fase inicial preparatória da resposta (seja qual for a forma em que ela se dê). O próprio falante está determinado precisamente a essa compreensão ativamente responsiva: ele não espera uma compreensão passiva, por assim dizer, que apenas duble o seu pensamento em voz alheia, mas uma resposta, uma concordância, uma participação, uma objeção, uma execução, etc. (os diferentes gêneros discursivos pressupõem diferentes diretrizes de objetivos, projetos de discurso dos falantes ou escreventes. (Bakhtin, 2016 a, p. 25-26, grifos meus)

Assim, prevê-se que cada gênero, em cada esfera, tenha suas especificidades quanto aos ângulos de interação, de dialogismo. De fato, Bakhtin (2016 a) afirma que "por mais monológico que seja um enunciado (por exemplo, uma obra científica ou filosófica" (p.58), ele sempre será resposta a outros elos de uma cadeia discursiva e gerará repostas, ainda que estas não sejam concretizadas numa interação imediata. Em D1, que, repito, só conhecemos na versão em português em 2016, temos evidências da recusa de Bakhtin em aceitar a existência do monologismo absoluto:

Todo enunciado é dialógico, ou seja, é endereçado a outros, participa do processo de intercâmbio de ideias: é social. Monólogo absoluto - expressão de uma individualidade - não existe; isto é uma ficção da filosofia idealista da linguagem, que haure a língua da criação individual. A língua é dialógica ("meio de comunicação") por natureza. O monólogo absoluto, que seria um monólogo fundado na língua, é excluído pela própria natureza da língua. (Bakhtin, 2016 b, 118)

Poderíamos dizer que, para Bakhtin, a relação entre os parceiros discursivos é de coautoria, já que não se espera uma resposta que apenas 
replique, sem autoria, a própria voz. Levanto a hipótese, como apontarei nas análises, que as redes sociais, em algum medida, operam no sentido de sempre colocar em contato parceiros discursivos que apenas dublem a voz do outro, registrando sua concordância com likes e aplausos. Uma passada de olhos nada científica por qualquer portagem do Instagram poderá mostrar que grande parte das respostas é composta por emojis de mãozinhas batendo palmas ou, no caso dos perfis de humor, de carinhas gargalhando. É um dialogismo baseado sempre na concordância ou o registro do hábito monologizante a que Bakhtin, como vimos anteriormente, se refere? ${ }^{6}$

Se o pensador russo não abordou nesse ensaio - nem poderia ter abordado - o tipo de interação das redes sociais, seu legado, como mostrei ao comentar aspectos de PPD, permite que pensemos como se dá a relação entre parceiros discursivos nessa esfera. Pensando especificamente no Instagram ${ }^{7}$, as possibilidades de interação começam quando se posta uma foto ou vídeo no perfil, que ficam armazenadas, como os vídeos da página @pera_toons, ou nos stories, que têm a efêmera duração de 24 horas e não são mais acessíveis após esse prazo.

Em relação a quem forma a rede de seguidores, o Instagram, desde sua origem, parece mais ligado ao interesse por temas, muito vezes banais, ou pelo perfil de famosos, do que pelo encontro de amigos ou colegas, como o Facebook. As pesquisadoras Pena Ramos e Analice Martins (2017) registram que a rede, "desenvolvida por dois engenheiros de programação, o norte-americano Kevin Systrom e o brasileiro Mike Krieger [...] surgiu para o público em outubro de 2010." e que , em 2017, "apresentou cerca de 800 milhões $^{8}$ de usuários ativos" (2017, p. 120). Lembram ainda que o Instagram

[...] possibilita a comunicação entre pessoas de todo o planeta, bastando apenas alguns elementos comuns: internet, dispositivo eletrônico (smartphone, tablet, notebook...) e o app em questão. Somados humano, hardware e software, a interação estará chancelada. O navegador estará apto a divulgar suas cenas cotidianas e a espiar a dos outros; inventivamente, a criar realidades e a expor ficções; [...].

\footnotetext{
${ }^{6}$ Evidência dessa tendência é o cerceamento ao botão "deslike" ou "dislike" em várias redes. A esse respeito, ver, por exemplo, https://canaltech.com.br/redes-sociais/Criador-do-botao-Curtir-doFacebook-explica-porque-o-Dislike-nunca-existira/. Acesso em: 15 jul. 2021 ou https://plugarideias. com/ 2021/04/07/ocultar-os-dislikes-youtube/. Acesso em: 15 jul. 2021.

7 Para mais informações sobre especificidades técnicas da rede, ver https://www.techtudo.com.br/ tudo-sobre/instagram.html e https://www.webartigos.com/artigos/principais-caracteristicas-doinstagram/142670. Acesso em: 08 jul. 2021.

${ }^{8}$ Sites especializados, como o Statista, apontam para a marca de 1,2 milhão de usuários em 2021. A esse respeito, consultar https://www.statista.com/topics/1882/instagram/. Acesso em: 07 ago. 2021.
} 
É sob a promessa de captura e compartilhamento de momentos do mundo, que versa o Instagram, em um trânsito intenso entre o singular e o banal - ou entre a singularização do banal e banalização do singular, como bem pretender o autor de cada perfil dessa rede. Ao usuário do aplicativo fica a escolha do conceito que desejar aplicar à sua rede social, personalizando e explorando sua textualidade, enquanto autor não só de textos, mas de si mesmo. (Ramos e Martins, 2017, p. 120-121)

O nome da rede nasce da junção das ideias de câmera instantânea e telegrama ${ }^{9}$, ou seja, em sua origem, era uma plataforma de divulgação de fotos com a possibilidade de uso de filtros e de ampla divulgação. Com a evolução da rede, o uso de vídeos se tornou mais corriqueiro e a quantidade de seguidores passou a ser um indicador de sucesso do perfil.

$O$ fato de um telegrama estar na origem do termo pode ser indicativo do tipo de reposta que se espera: um telegrama não pressupõe uma reposta com outro telegrama, mas prevê causar em que o lê a ciência de algum fato. O Instagram seria, então, uma plataforma com tendências monologizantes, em que a reposta que se espera é a curtida, o comentário elogioso, a eterna concordância? Retomarei essa discussão nas análises.

Uma discussão importante em GD (Bakhtin, 2016 a), que pode levar a reflexões produtivas sobre as redes, é a questão da natureza mais ou menos familiar, íntima, de certos gêneros, e de suas implicações para o estilo, e, portanto, para o discurso:

Matizes mais sutis do estilo são determinados pela índole e pelo grau de proximidade pessoal do destinatário em relação ao falante nos diversos gêneros familiares de discurso, por um lado, e íntimo, por outro. A despeito de toda a imensa diferença entre gêneros familiares e íntimos (e, respectivamente, os estilos), eles percebem igualmente o seu destinatário em maior ou menor grau fora do âmbito da hierarquia social e das convenções sociais, por assim dizer, "sem classes". Isso gera uma franqueza especial do discurso (que no discurso familiar chega às vezes ao cinismo. Nos estilos íntimos, isso se traduz no empenho voltado como que para a plena fusão do falante com o destinatário do discurso. [...] (p. 65)

\footnotetext{
${ }^{9}$ Ver https://www.techtudo.com.br/listas/2018/10/o-que-significa-instagram-veja-a-origem-dosnomes-de-redes-sociais.ghtml. Acesso em 08 jul. 2021
} 
Embora Bakhtin não exponha de maneira didática o que seriam os gêneros familiares ou íntimos, baseia suas reflexões na relação entre os falantes. Como é a relação entre os parceiros nas redes?

No Facebook colecionam-se "amigos". Em geral, a rede sugere que se amplie seu número indicando "Pessoas que talvez você conheça". As pessoas que têm acesso ao conteúdo de uma página particular do Facebook, adicionadas como "amigos", muitas vezes conhecem o dono ou dona da página fora das redes. Ou seja, ao menos em suas origens, essa rede social estreitava laços que existiam de modo presencial para um ambiente virtual, embora sempre tenha havido a possibilidade de interagir com desconhecidos, sobretudo nas comunidades. A ideia da interação primordial no Facebook ser com amigos está nas definições que pesquisadores dão à própria rede, como lembra Emediato, para quem o Facebook, "que foi concebido para ser um dispositivo eletrônico para interagir com os amigos [...] parece estar se construindo como um espaço aberto a todos os aspectos da retórica humana" (2015, p.191). Nesse mesmo sentido, sobre as origens da rede, Kirkpatric assevera que 0 Facebook

[...] foi explicitamente concebido e projetado por Zuckerberg e seus colegas como uma ferramenta para melhorar os relacionamentos com as pessoas que você conhece pessoalmente - seus amigos no mundo real, conhecidos, colegas de classe ou de trabalho. [...] essa é uma diferença fundamental entre o Facebook e outros serviços semelhantes - e a cada momento gera um conjunto específico de desafios para a empresa. $\mathrm{Na}$ maioria das vezes, o Efeito Facebook se faz sentir na esfera do cotidiano, em um nível de intimidade entre um pequeno grupo. Ele pode tornar a comunicação mais eficiente, cultivar a familiaridade e aumentar a intimidade [...] (Kirkpatric, 2011, p. 20)

Se, na origem, o Facebook era uma espaço de encontros e reencontros com amigos, o efeito da incorporação de "amigos de amigos" acabou levando muitas pessoas que usam a rede a conexões com usuárias e usuários desconhecidos, mostrando em escala mundial o que, na década de 1960, Stanley Milgram propôs como a teoria dos seis graus de separação, ou seja, seria possível chegar a qualquer pessoa do mundo com apenas cinco conexões ${ }^{10}$.

10. $\mathrm{O}$ estudo de Milgram baseou-se num experimento físico, em que pessoas precisavam fazer chegar a outras que elas desconheciam um envelope. Não podiam procurar diretamente essa pessoa 
No Instagram, arregimentam-se "seguidores". Para quem cria os perfis, o número de seguidores é um indicador de sucesso e de possibilidade de lucrar com as postagens (pela inserção de promoções de diversos produtos, por exemplo). Na minha experiência particular, pessoas aleatórias pedem para seguir meu perfil, talvez motivadas por algum comentário que faço em postagens dos perfis que sigo, e, provavelmente esperando que eu a siga de volta. Há um ou outro amigo de Facebook que aparece também nessa minha rede, e, nesse caso, aceito a pessoa como seguidora. De qualquer maneira, as relações nessas duas redes partem de pressupostos diversos: no Instagram, por algum interesse sobre 0 conteúdo, pede-se para seguir alguém. No Facebook, os usuários solicitam sua amizade, ou por, de fato, serem pessoas conhecidas ou amigas, ou por terem alguma identificação com o que leem em sua página. ${ }^{11}$

Em ambas as redes, no entanto, parece haver algo de íntimo entre quem divulga postagens e quem as lê: emprega-se amiúde o registro da confidência, sem uso de formas de tratamento que pudessem marcar uma hierarquia social entre usuários. Pelo que percebo, os usuários em geral empregam o pronome de tratamento "você" na interações, dispensando as formas de tratamento "O senhor", "A senhora". Na página do @pera_toons, que é em italiano, acontece o mesmo: usa-se a forma "tu" para a interação direta, nunca a forma "Lei"12. Na próxima sessão, destacaremos alguns registros e refletiremos sobre os sentidos que esse fenômeno ajuda a criar.

\section{AS APARÊNCIAS ENGANAM?}

A postagem reproduzida na sessão inicial deste artigo gerou várias repostas. Compilo aqui a materialidade verbal da tira animada, meu comentário e as respostas que este suscitou .

desconhecida, mas tinham que fazer o envelope circular entre seus contatos. Para saber sobre essa teoria, sugiro a leitura do artigo Redes sociais e relacionamentos de amizade ao longo do ciclo vital. (Souza; Santos, 2017. Disponível em <http://pepsic.bvsalud.org/scielo.php?script=sci_arttext \&pid= S0103-84862011000100006>. Acesso em: 19 jul. 2021)

${ }^{11}$ Como a extinta rede Orkut, o Facebook também tem suas comunidades, onde se encontram pessoas não pelo conhecimento prévio que têm umas das outras, mas pelo interesse em algum tema.

${ }^{12} \mathrm{Em}$ italiano, a distinção é bastante evidente. No tratamento mais familiar, os verbos e pronomes ficam na segunda pessoa; no mais formal, vão para a terceira pessoa. Numa situação presencial, por exemplo, uma pessoa desconhecida não empregaria o pronome "tu" para se dirigir a outra que percebe como "não jovem", como aconteceu nos comentários que rebateram meu comentário. Voltarei a este ponto nas análises. 
QUADRO 1 - Texto da tirada animada - tradução literal minha para o português e original em italiano

\begin{tabular}{|l|l|}
\hline Frame 1 & $\begin{array}{l}\text { África, tem gente que não percebe como você é bonita. } \\
\text { Original: } \text { Africa, c'è gente che non si rende conto } \\
\text { quanto sei bella }\end{array}$ \\
\hline Frame 2 & $\begin{array}{l}\text { Isso porque a aparência em Gana. } \\
\text { Original: Questo perché l'apparenza in Ghana }\end{array}$ \\
\hline
\end{tabular}

QUADRO 2 - Comentário inicial, reações e respostas - tradução literal minha para o português e original em italiano

\begin{tabular}{|c|c|}
\hline Comentário 1 & $\begin{array}{l}\text { A segunda parte de uma suposição que a aparência } \\
\text { da África seja feia. É bastante desrespeitosa, no Brasil } \\
\text { você seria logo processado. São diferenças culturais, } \\
\text { gosto de acompanhar a mídia italiana e percebo que, } \\
\text { neste sentido, vivemos em mundos diferentes. Pense } \\
\text { nisso. Está dizendo que a aparência do continente é } \\
\text { feia. Como você se sentiria com uma piada desse tipo } \\
\text { sobre sua casa? } \\
\text { Original: La seconda parte da una suposizione }{ }^{13} \text { (sic) che } \\
\text { l'apparenza dell'Africa sia brutta. É abbastanza } \\
\text { disrespettosa, in Brasile saresti processato subito. Sono } \\
\text { differenze culturali, mi.piace accompagnare la midia italiana } \\
\text { e vedo che, in questo senso, viviamo mondi molti diversi. } \\
\text { Pensaci. Sta dicendo que l'apparenza del continente è } \\
\text { brutta. Come ti sentiresti con una battuta del genere sulla } \\
\text { tua casa? }\end{array}$ \\
\hline $\begin{array}{l}\text { Respostas } \\
\text { [...] indica que o } \\
\text { nome do usuário e o } \\
\text { vocativo (nome do } \\
\text { usuário que fez o } \\
\text { comentário que se } \\
\text { está rebatendo) } \\
\text { foram retirados para } \\
\text { a reprodução neste } \\
\text { artigo. }\end{array}$ & $\begin{array}{l}\text { 1. [...] Vê se dá uma risada, meu deus, que droga! } \\
\text { Original: [...] ma fatti una risata dio cane! } \\
\text { 2. [...], mas, o que você tá dizendo não foi para } \\
\text { ofender ninguém, viva, por favor. Foi pela } \\
\text { brincadeira que Gana tem o som de engana. } \\
\text { Original: [...], ma cosa dici non è stata fatta per } \\
\text { offendere nessuno, vivi per piacere. Ė stata fatta per } \\
\text { la battuta che Ghana ha il suono di inganna. } \\
\text { 3. RESPOSTA FEITA PELA AUTORA DA CRÍTICA } \\
\text { INICIAL, endereçada a quem escreveu a }\end{array}$ \\
\hline
\end{tabular}

${ }^{13}$ Há um erro de ortografia aqui: o correto é "supposizione". 


\begin{tabular}{|l|l|}
\hline resposta 2 \\
[...] eu entendi isso. Mas não se pode fazer \\
qualquer coisa só pra não perder a piada. E se a \\
aparência engana, é porque o continente seria \\
feio na aparência e bonito na essência. É \\
ofensivo do ponto de vista discursivo. Ainda que \\
a intenção não tenha sido essa, como acredito \\
que não tenha sido, o efeito é ofensivo. \\
Original: [...] ho capito questo. Ma non si può tutto \\
pur di non perdere la.battuta. E se l'apparenza \\
inganna, è perchè il continente sarebbe brutto in \\
apparenza e bello in essenza. É offensivo dal punto \\
di vista discorsivo. Anche se l'intenzione non era \\
questa, come credo che non fosse, l'effetto è \\
ofensivo. \\
4) [...] Vê se ri um pouco e cala a boca \\
Original: [...] ma fatte do riste e statte (sic) zitta \\
5) [...] Ria um pouco \\
Original: [...] fatti una risata \\
6) [...] puta que pariu, ERA PRA FAZER UMA PIADA, \\
NÃO SE QUER OFENDER NADA NEM NINGUÉM \\
EINSTEN \\
Original: [...] ma porca troia, ERA PER FARE LA \\
BATTUTA, NON SI VUOLE OFFENDERE NIENTE E \\
NESSUNO EINSTEIN \\
7) [...] Minha nossa, vê se ri de uma tirada \\
puramente irônica, quanta masturbação mental \\
Original: [...], Madonna mia, ma ridi ad una \\
battuta puramente ironica, quante seghe mentali \\
8) [...] se você prestar atenção, [verá que] se disse \\
que tem gente que não percebe, não que pareça \\
em geral feia, mas só que há pessoas que a \\
veem assim. Como com qualquer coisa. \\
Original: [...] se fai attenzione ha detto che c'è \\
gente che non si rende conto, non che sembri in \\
generale brutta, ma solo che ci sono persone che la \\
vedono cosi. Come con ogni cosa \\
9) Resposta excluída \\
\end{tabular}


10) Resposta da autora da crítica inicial para a reposta excluída: [...] um pouco de educação, por. favor. não concordar. é humano, não precisa empregar essa linguagem. Se um grupo não sabe receber uma crítica, não poderá melhorar nunca. Muito. triste seu modo de se dirigir a uma pessoa que simplesmente mostrou uma visão de mundo.

Original: [...] un $\mathrm{po}^{\prime}$ di cortesia, per.piacere. non essere.d'accordo è umano, non c'è bisogno di impiegare questo linguaggio. Se un gruppo non sa ricevere uma critica, non potrà mai migliorare. Molto.triste il suo modo di rivolgersi ad una persona che ha semplicemente mostrato una visione di mondo.

11) $[. .$.$] e se fosse sobre a Europa? Ah, nenhum$ problema, né, faça-me o favor. Depois, colocou a África somente porque tem Gana, não porque a África "parece feia" ou algo assim. Além do mais, no vídeo está fazendo um elogio à África (ou seja, diz que ela é muito bonita). Se a gente reclama disso não se podem mais fazer piadas em geral, se sempre vai ter alguém pra criticar. Por favor, não enche a paciência sobre este post que ninguém, além de você, considerou discriminatório e volta para o Facebook. Ah, e você também deveria aceitar um pouco de críticas que tantos te fizeram, ou seja, esse é só um meme para brincar e não ofende ninguém.

Original: [...] se lo faceva sull'Europa? Ah nessun problema eh, ma fammi il piacere. Poi ha messo I'Africa solo perché c'è Ghana, non perché l'Africa "sembra brutta" o cose simili. Oltretutto nel video sta facendo un complimento all'Africa (ossia dice che sia molto bella). Se ci si lamenta per questo non si possono fare più battute in generale, se ci deve essere sempre qualcuno a criticare. Per favore non rompere le scatole sotto questo post che nessuno ha trovato discriminatorio tranne te e torna su Facebook. Ah e anche te dovresti accettare un po' di critiche che ti hanno fatto in molti, ossia che questo è solo un meme fatto per scherzare e non offende nessuno. 
12) [...] volta pro Facebook, deixa o instagram pros jovens, por favor

Original: [...] torna su Facebook, instagram lo lasci ai ragazzi per piacere

O uso do verbos na segunda pessoa do singular em italiano, como se percebe, por exemplo, nos imperativos fatti (resposta1), vivi ( reposta 2) e torna ( resposta 12),entre outros, atesta o uso de uma linguagem familiar. No registro formal, a forma desses imperativos seria si faccia, viva e torni De fato, em italiano, usa-se a forma na terceira pessoa para situações formais, pessoas desconhecidas, mas em geral, aos familiares, ainda que mais velhos, se emprega a segunda pessoa.

Parece haver a percepção de que quem escreve a crítica não é jovem, como se vê na reposta 12 . Ao sugerir que a pessoa deixe o Instagram para os jovens, quem escreveu essa reposta dá a entender que se dirige a alguém mais velho. Essa percepção pode se dar também pela significativa presença de pontos entre as palavras na resposta 10, feita pela autora da crítica, o que poderia demostrar falta de habilidade com dispositivos eletrônicos por parte de quem está escrevendo. Mesmo assim, mantém-se o uso do registro informal. Para Bakhtin, como mostrei anteriormente, esse registro é típico de gêneros em que há alto grau de franqueza e até cinismo. Nas respostas 6 e 7, com os termos "porca troia" (algo como "puta que pariu, literalmente "porca puta") e "seghe mentali" ("masturbações mentais"), evidencia-se essa franqueza.

Houve uma resposta (número 9$)^{14}$ que foi excluída da rede. Não pude levantar como se deu essa exclusão. Foi a única que gerou uma réplica da autora da crítica. Com a exceção dessa exclusão, manteve-se o registro da discussão no perfil @pera_toons, sem que houvesse manifestação explícita do usuário a quem o perfil pertence.

A ideia de que se trata de perfil cômico e que, por isso, não poderia haver caráter ofensivo em suas colocações, está implícita nas interações que sugerem que a autora da crítica dê risada, e explícita em termos como "piada puramente irônica" (reposta 7) e na reclamação de que não se podem mais fazer piadas, na resposta 12 . Há, ainda, a percepção de que a discordância sobre a graça da piada deve ter sido causada pelo fato de a pessoa que fez críticas não a ter entendido, como se nota nas respostas 8 e 11.

A colocação de uma crítica, do embate, a inserção de uma resposta

\footnotetext{
${ }^{14}$ Na postagem, não há indicação de reposta excluída. Discursivamente, a reposta 10 deixa registado, inclusive por usar o nome do perfil excluído como vocativo, de que houve essa intervenção

considerada bastante agressiva. Talvez por isso tenha sido excluída.
} 
em ângulo dialógico de não concordância parece não ser aceita pela maioria dos seguidores. Isso pode ser indício de uma prescrição implícita desse rede. Por um lado, os seguidores são desejáveis; por outro, as relações dialógicas entre usuário de perfil e seguidores subentendem-se como de concordância. Os "hábitos monológicos" citados por Bakhtin (2010, p. 338) em suas reflexões sobre a crítica a Dostoiévski fazem-se entrever nesse tipo de interação no Instagram. Procuram-se parceiros discursivos que atuem dublando o que leem e veem.

Nesse sentido, cabe uma referência breve ao extenso e profundo trabalho desenvolvido por Amorim $(2000,2015,2007)^{15}$. Para a autora, há três formas de conhecimento ou saber: Lógos, Mythos e Métis, que se diferenciam pela natureza do diálogo e da alteridade implicada em cada uma delas. O conhecimento e as relações de alteridade baseados num saber demonstrativo estariam no domínio de Logos, que, para a autora, tem início com os gregos e "funda, de um só lance, a filosofia, a matemática e a ciência (Amorim, 2000, p. 2). Em oposição ao Logos, o saber do tipo Mythos baseia-se na narrativa e é validado não pela oposição entre o que pode ser demostrado como verdadeiro ou falso, mas por aquilo que consegue escapar do esquecimento. Enquanto for lembrado, o saber do tipo Mythos é válido.

Sobre as relações de alteridade, Amorim destaca que em Logos existe uma relação ente "eu" e "ele", ou seja, o diálogo se dá com o objeto, com o conhecimento, e não de maneira horizontal com um "tu", como acontece no saber Mythos, em que haveria a alternância de sujeitos e a preponderância do dialogismo. A autora não hierarquiza os saberes, apenas reconhece seu funcionamento. Tematiza, também, um saber do tipo Métis, que se basearia na ação, na eficácia, não no discurso. Não há dialética, como em Logos, ou dialogia, como em Mythos, mas a ação, a produtividade, o resultado. A relação com o outro, em Métis, para Amorim, é pautada por um "princípio de identificação, ou, se preferirmos, de mimetismo" (2000, p. 7).

A autora reconhece que os saberes funcionam nos diversos campos de atividade humana em concomitância, mas questiona os impactos da preponderância de Métis em algumas esferas da contemporaneidade. Afirma que:

\footnotetext{
${ }^{15}$ A obra Raconter, démontrer, ...survivre (Amorim, 2007) não tem tradução para o português. Optei por trazer citações do registro da palestra Alteridade e formas de saber (2000) que a pesquisadora fez no Brasil sobre tema afim. O registro escrito da palestra está disponível em https://www.fe.unicamp.br/eventos/br2000/trabs/1190.doc. Acesso em: 05 ago. 2021.
} 
As três formas de saber, Mythos, Logos e Mètis ${ }^{16}$, fazem parte da riqueza humana e são igualmente necessárias. No âmbito individual, a cada situação com que nos defrontamos, somos convocados a julgar e decidir qual delas deverá predominar e como as restantes devem trabalhar a seu serviço. Sendo formas radicalmente distintas, a articulação entre elas, embora necessária, é algo sempre complexo. Não se trata de buscar harmonia, equilíbrio e tampouco superação dialética. Trata-se de arranjos pontuais, sempre instáveis e problemáticos, e que correspondem ao que cada sujeito, individual ou coletivo, julga ser o melhor possível ou o menos pior, em uma dada situação. No âmbito coletivo, segundo o contexto sócio-histórico, é possível observar a dominância de uma forma ou de outra.

[...]

Assim, encontramo-nos nos domínios de Hermès, deus grego mètis por excelência, senhor dos signos e da escrita, mestre na arte da comunicação, seja clarificando seja trocando os sinais e apagando os rastros, a fim de desnortear seu interlocutor. O que poderia explicar a presença massiva dos experts em comunicação e marketing que formatam as relações sociais. Hermès é também o grande inspirador dos comerciantes e dos ladrões. Ainda no mundo grego antigo, o herói Ulysses encarna aquela que é a habilidade maior de mètis: a polimorfia. Mudar de forma, de aparência, "virar a casaca" e "dançar conforme a música", abrindo mão de qualquer referência identitária ou singularizante. (AMORIM, 2015, p.162)

Em diversos escritos (2000, 2007, 2015), Amorim propõe que o mundo pós-moderno apresenta um predomínio discurso de relações pautada num tipo de saber Métis, em que se busca a metamorfose com o outro. Em termos dialógicos, essa metamorfose tem efeito de apagamento de vozes e identidades: ainda que o dialogismo se dê também pela concordância, há nas relações dialógicas, espaço para o reconhecimento e 0 acolhimento das singularidades.

Dialogando com tais reflexões, proponho que o tipo de relação de alteridade que as respostas analisadas neste artigo apontam como desejável no Instagram baseia-se num saber do tipo Métis, em que a supressão das diferenças é desejável. A percepção de que o Facebook seria

\footnotetext{
${ }^{16}$ Observa-se no original, em português, que os acentos de algumas palavras obedecem às prescrições da língua francesa. Mantivemos a grafia do artigo.
} 
o lugar da polêmica poderia apontar para a circulação de sentido de que nessa rede mais antiga haveria espaço para relações discursivas de outra ordem, baseadas em Lógos ou Mythos.

Assim, um outro que não atua segundo o saber Méthis, que acentua a natureza dialógica dos enunciados numa esfera que parece tender para o hábito monologizante, é rechaçado. As repostas 11 e 12, que sugerem que a autora da crítica volte para o Facebook, são exemplares nesse sentido: a permanência no grupo de seguidores daquele perfil Instagram não é bem-vinda se há embate, se a reposta não está em sempre sob o ângulo da concordância. Essas repostas trazem ainda o sentido de que o Facebook seria um lugar para gente mais velha, onde haveria espaço para o embate. Cria-se, então, o dilema dialógico: seguidores são necessários no Instagram, mas devem desejar a metamorfose com o perfil, não o diálogo. Quem quer "bater boca", deveria ir para o Facebook.

No "docudrama" O dilema das redes (Orlowski, 2020) apresenta-se a um público amplo a atuação de algoritmos que vasculham nossas preferências e nos fazem navegar e interagir em determinados sites e com determinadas pessoas. É uma obra construída com elementos de documentário, o que gera um efeito de veracidade e, nesse caso, de grande inquietação pela revelação de coerções no mundo virtual. A obra trata especificamente de como o Facebook mostra aos usuários conteúdos que os potencializem como consumidores, seja de produtos, seja de ideias. Orlowski, portanto, apresenta, esteticamente, a natureza constitutiva do Facebook como esfera de interação, que criaria uma ilusão de liberdade, de autoria, de escolha, mas que, de fato, colocaria os usuários como marionetes de um algoritmo. E esse lugar, nas análises que apresentei, é apontado como o palco que acolheria o debate, a crítica.

\section{UM COPO DE MAR}

Partindo de uma experiência catalisadora, construí um objeto de análise, qual seja, a circulação de sentidos de interdição da voz de usuários que apresentem certas caraterísticas no Instagram. No corpus de análise recortado, percebe-se a indicação de que o Facebook seria o lugar para pessoas mais velhas, chatas, que querem polemizar, discutir.

O embate que percebo nessa gota de discurso, ao conversar com ela pelas lentes dialógicas, forjadas no contado com a obra de Bakhtin e do Círculo, apontam para uma força monologizante nos discursos dos usuários do Instagram que foram aqui recortados; essa força remete ao trabalho de Amorim ( 2000, 2007, 2015), que problematiza as próprias possibilidades de conhecimento e de saber segundo parâmetros referentes 
aos tipos de relação discursiva entre interlocutores. Nesse diálogo, percebo o saber do tipo Métis, apoiado na metamorfose entre interlocutores, na interdição de vozes, na eficácia do pragmatismo: "O que foi feito para rir não foi feito para pensar ou discutir", parecem dizer os detratores da crítica à postagem que foi aqui reproduzida. "O Facebook é lugar de gente, velha", parecem dizer esses mesmos detratores.

Discute-se atualmente sobre com quem se fala no Facebook, e essa discussão foi estetizada pelo já citado "docudrama" de Orlowski, que mostra as forças que conduzem as interações nesse ambiente, que trataria usuários como marionetes de um algoritmo.

As pessoas estariam então, fadadas a falar sozinhas ou em "relações monológicas" nas redes? Será que aí as aparências, em que se tem a ilusão de uma esfera potencializadora do diálogo, de fato, enganam? Que se estude o fenômeno; aqui me propus a flagrar uma gota de discurso em que o percebo. Mas, impregnada da filosofia dialógica (e da crença estética na Força), tendo a hipotetizar que forças centrífugas podem vencer 0 exército de clones, que sempre haverá um palco, ainda que seja um copo de mar, para, em imperfeito dialogismo, navegarmos, opinarmos, reclamarmos, refletirmos, refratarmos e qualificarmos interlocutores.

\section{REFERÊNCIAS}

AMORIM, Marília. Alteridade e formas de saber. Palestra. Instituto de Psicologia, Universidade Federal do Rio de Janeiro, 2000. Disponível em https://www.fe.unicamp.br/eventos/br2000/trabs/1190.doc. Acesso em: 01 ago. 2021.

AMORIM, Marília. Cronotopo e exotopia. In. Brait, Beth (org.) Bakhtin. Outros conceitos-chave. São Paulo: Contexto, 2006. p. 95-114.

AMORIM, Marília. Raconter, démontrer,... survivre. Formes de savoirs et de discours dans la culture contemporaine. Ramonville Saint-Agne: Éditions Érès, 2007.

AMORIM, Marília. Marcas enunciativas da relação saber-poder na cultura contemporânea. Revista Organon, Universidade Federal do Rio Grande do Sul, v.30, n. 59, 2015, p.155-184. Disponível em https://seer.ufrgs.br/ organon/article/view/57146. Acesso em: 01 ago. 2021.

BAKHTIN, Mikhail. Problemas da poética de Dostoiévski [1963]. 5. ed. Revista. Trad. Paulo Bezerra. Rio de Janeiro, Forense Universitária, 2010.

BAKHTIN, Mikhail. Os gêneros do discurso. [1952-1953].Organização, 
tradução e notas Paulo Bezerra. São Paulo: Editora 34, 2016 a.

BAKHTIN, Mikhail. Diálogo I. A questão do discurso dialógico. [?]. In. Os gêneros do discurso. Organização, tradução e notas Paulo Bezerra. São Paulo: Editora 34, 2016 b. p. 113-124.

BAKHTIN, Mikhail (Volóchinov). [1929] Marxismo e filosofia da linguagem. Problemas fundamentais do Método Sociológico na Ciência da Linguagem. Trad. Michel Laud e Yara Frateschi Vieira. Sâo Paulo: Editora Hucitec, 2004.

EMEDIATO, Wander. Discurso e web: as múltiplas faces do Facebook. Revista da ABRALIN, v. 14, n. 2, 2015. Disponível em https://revista.abralin.org/index.php/abralin/article/view/1262. Acesso em 07 ago. 2021.

KIRKPATRICK, David. 0 efeito Facebook. Trad. Maria Lúcia de Oliveira. Rio de Janeiro: Intrínseca, 2011.

ORLOWSKI, Jeff. (direção). O DILEMA DAS REDES. Estados Unidos: Netflix, 2020. (94 min). Disponível em www.netflix.com. Acesso em: 05 ago. 2021.

RAMOS, Penha Élida G. T; MARTINS, Analice de Oliveira. Reflexões sobre a rede social Instagram. Do aplicativo à textualidade. Revista texto Digital, v.14. n.2, 2018.p. 117-133. Disponível em: https://periodicos. ufsc.br/index.php/textodigital/article/view/1807-9288.2018v14n2p117 Acesso em: 07 ago. 2021.

VOLÓCHINOV, Valentin. Marxismo e filosofia da linguagem. Problemas fundamentais do método sociológico na ciência da linguagem. Trad. Sheila Grillo e Ekaterina Vólkova Américo. São Paulo: Editora 34, 2017.

ZAVALA, Íris. O que estava presente desde a origem. Trad. Fernando Légon e Diana Araújo Pereira. In. BRAIT, Beth. Bakhtin. Dialogismo e polifonia. São Paulo: Contexto, 2009. p.151-166.

Recebido em: 08/08/2021

Aceite em: 08/12/2021 